\title{
Optimal liquidity provision through a demand deposit scheme: The Jacklin critique revisited*
}

\author{
Alexander Zimper
}

January 27,2012

\begin{abstract}
We derive conditions such that optimal liquidity provisions through a demand deposit scheme can be sustainably implemented in a subgame perfect Nash equilibrium under the assumption that renegade investors have free access to ex-post asset markets. As our qualitative main finding we demonstrate that such sustainability is more likely for "poor" than for "rich" scheme participants in terms of future income. By establishing sustainability for low future income populations, our formal analysis therefore offers an important qualification of Jacklin's (1987) influential claim that an optimal demand deposit scheme is not sustainable whenever there exists the possibility of an ex-post asset market.
\end{abstract}

Keywords: Jacklin critique, financial intermediation, asset markets JEL Classification Numbers: D82, G21, G32.

*I thank Alex Ludwig, the editor Wolfgang Leininger, and an anonymous referee for helpful comments and suggestions. Financial support from Economic Research Southern Africa (ERSA) is gratefully acknowledged.

${ }^{\dagger}$ Department of Economics, University of Pretoria, Private Bag X20, Hatfield 0028, South Africa. E-mail: alexander.zimper@up.ac.za 


\section{Introduction}

In the wake of the recent global financial markets crisis - and the even more recent EU debt crisis - there exists renewed interest in understanding better the welfare implications of financial intermediaries and asset markets. Popular opinion has it these days that asset markets and financial intermediaries, i.e., banks, are doing more harm than good to a society's overall welfare. In contrast, economic theory claims that financial intermediaries and asset-markets are welfare-improving because their existence allows for the mitigation of all kinds of risks. As a consequence of these risk-mitigation effects risk-averse investors become encouraged to invest in risky - but on average profitableprojects which would not become reality otherwise. Quite surprisingly though, beyond this standard insurance argument the theoretical literature offers very little in terms of conclusive results about welfare implications of different financial arrangements such as financial intermediaries, on the one hand, and asset markets, on the other hand.

The focus of this paper is on the question whether financial intermediaries can achieve welfare maximization when they coexist with asset markets. More specifically, we investigate conditions such that financial intermediation in the form of a demand deposit scheme can sustainably implement optimal liquidity allocations if there is the possibility of an ex-post asset market. Recall that in a demand deposit scheme economic agents pool their financial resources through a financial intermediary (i.e., the "bank") who invests them in a project and pays a contracted stream of interest to the agents. Bryant (1980) and Diamond and Dybvig (1983) describe situations in which a demand deposit scheme can implement a welfare maximizing liquidity allocation that is not implementable through an ex-ante asset market. Moreover, Wallace $(1988,1990)$ demonstrates the formal equivalence of the 'good' equilibrium in the Diamond and Dybvig model, on the one hand, and the allocation achievable by welfare maximization under asymmetric information, on the other hand. Initiated by Jacklin's (1987) highly influential article, however, the relevance of this welfare advantage of demand deposits over asset markets has subsequently come under heavy scrutiny (cf., e.g., Haubrich 1988, Haubrich and King 1999, Jacklin 1993, von Thadden 1997, 1998, 1999, Wallace 1988, 1990, chapter 12.2.4 in Tirole 2006). As a consequence of the so-called 'Jacklin critique' there now appears to be a common perception in the literature that a demand deposit scheme could only outperform asset markets under the - rather unrealistic assumption - that there exist severe trading restrictions on ex-post asset markets. ${ }^{1}$

\footnotetext{
${ }^{1}$ The perception that demand deposits cannot improve welfare over market-based solutions in realistic situations also gives rise to the popular opinion that asset markets may perform better from an overall perspective since they are not vulnerable to bank runs, (cf., e.g., the textbook treatments in Bolton and Dewatripont 2005, and in Freixas and Rochet 2008). Indeed, Diamond and Dybvig's (1983) seminal
} 
More precisely, Jacklin (1987) argues that the demand deposit scheme cannot sustainably implement the optimal liquidity allocation if there is the possibility of an ex-post asset market. Jacklin's - rather informal-argument considers a renegade agent who does not join the demand deposit scheme but rather privately invests in the project. In case this agent turns out to have a high desire for liquidity, he would then later-on sell the corresponding asset on the ex-post market to scheme participants. According to Jacklin, such renegade agent could always achieve an asset-price that is sufficiently high to give him a strict incentive for not joining the demand deposit scheme provided that all other agents join this scheme. Technically speaking, according to the 'Jacklin critique' a second-best liquidity allocation through a demand deposit scheme is thus not implementable in a subgame-perfect Nash equilibrium whenever agents have the outside option of making private investments which they can sell later-on on some ex-post asset market.

We formally investigate the validness of this claim by considering a large population of ex-ante identical agents who face a portfolio maximization problem whereby each agent decides about how much of his initial wealth to invest in an illiquid long-term project or to hold as money, respectively. We further assume that each agent's future desire for liquidity is private knowledge whereby the fraction of liquidity types in the population is known. In contrast to the standard insurance argument in favor of financial intermediation, we establish welfare benefits for the demand deposit scheme in a completely risk-neutral environment so that insurance considerations do not matter. ${ }^{2}$ As an intermediate result of our analysis (Proposition 3) we obtain that the welfare maximizing liquidity allocation can be sustainably implemented through a demand deposit scheme if and only if a prospective renegade agent can only expect a rather low asset-price on the ex-post asset market. In a next step we formally link this asset price to the renegade agent's market power on the ex-post asset market (Proposition 4). As our qualitative main insight we proceed to argue that the structure of the agents' intertemporal income streams has a crucial impact on the renegade agent's market power and thereby on the sustainability of the optimal demand deposit scheme. More specifically, our analysis distinguishes between two benchmark scenarios with respect to the scheme-participants'

article is foremostly interested in the possibility of bank runs due to the existence of a 'bad' demand deposit equilibrium. Although the - non-trivial - question about the possible emergence of strategic bank runs is beyond the scope of the present paper, the interested reader is referred to Postlewaite and Vives (1987), Rochet and Vives (2004), Goldstein and Pauzner (2005), Zimper (2006) and the literature cited therein.

${ }^{2}$ I am grateful to Jürgen Eichberger for pointing out to me that positive welfare effects from financial intermeditation may be due to relaxed budget constraints in the aggregate and therefore also apply to a risk-neutral environment; (cf. Remark 1 in Section 2). 
future income:

- If the agents receive a high future income - beyond the contracted income of the demand deposit scheme - a high expected asset-price is plausible because a prospective renegade agent will face a large number of prospective buyers (i.e., all schemeparticipants with a low desire for liquidity) who might engage in a fierce Bertrand price competition for his asset (Proposition 5).

- If, in contrast, the agents receive a low future income, any subgame-perfect Nash equilibrium involves - on the demand side of the ex-post asset market - only low type scheme-participants who have misreported their type in order to obtain liquidity through the demand deposit scheme. Under suitable model-parameter valuese.g., a large proportion of agents with a high desire for liquidity; a strong desire for liquidity by such agents; a low return on the investment project - there will be only one prospective buyer in any pure-strategy Nash equilibrium to the effect that a rather low expected asset-price obtains in the ex-post asset market now modeled as a bilateral bargaining situation (Theorem).

Our formal findings suggest that the original formulation of the 'Jacklin critique' is too general and that its validness strongly depends on the future income situation of the considered population as well as on the (expected) return of the investment project. Simply speaking, the 'Jacklin critique' appears to be foremostly valid for populations of people who receive high future income which gives them-beyond the demand deposit scheme sufficient liquidity to purchase the asset at a high price in some ex-post asset market. In contrast, the 'Jacklin critique' does not necessarily apply to a population of people with low future income who can only use the liquidity resources provided through the demand deposit scheme in case they want to purchase the asset on the ex-post market. For such low future income population there is no strong incentive to become a renegade agent because the expected price on the ex-post market tends to be rather low. Normatively interpreted our findings thus establish that a sustainable demand deposit scheme can be welfare maximizing for (i) people who cannot expect high income levels in the near future combined with (ii) a low (expected) return of the investment project. Positively interpreted our findings suggest that (i) the participants in existing demand deposit schemes would be pensioners or long-time students rather than, say, investment bankers or CEOs whereby (ii) such schemes would be rather used to finance projects with low (expected) returns.

The remainder of our analysis is structured as follows. Section 2 presents the basic model and characterizes the autarkic as well as the first best liquidity allocation under the 
assumption of risk-neutral agents. In Section 3 we derive the second best allocation and show how it can be implemented through a demand deposit scheme. Section 4 describes the situation of a prospective renegade agent and characterizes the sustainability of the optimal demand deposit scheme in terms of the asset-price obtainable in the ex-post asset market. The high future income scenario is investigated in Section 5 whereby we argue that the 'Jacklin critique' is most plausible for this scenario. In contrast, Section 6 considers the low future income scenario for which sustainability of the optimal demand deposit scheme obtains for suitable values of the model-parameters. Finally, Section 7 concludes with a discussion of the related literature.

\section{The basic set-up}

Our agents live in a three-period world in which they receive exogenous income $I_{0}=$ 1 and $I_{1} \geq 0$ in periods 0 and 1 , respectively. We thereby interpret $I_{0}$ and $I_{1}$ as 'additional' income; that is, this income is freely disposable for investment purposes on top of whatever income the agent has spent on his every-day consumption. We will at first focus on welfare-optimal allocations whereby we are exclusively interested in the agents' investment decisions subject to the budget constraint as given by the period 0 income $I_{0}$. Only when we check in subsequent sections for the sustainability of the optimal demand deposit scheme, the period 1 (="future") income $I_{1}$ becomes relevant because it enters into the budget constraint for the ex-post asset market situation.

More specifically, we consider at first an autarkic investment situation in which a time-patient, risk-neutral agent decides in period 0 how much of his period 0 income $I_{0}$ he will hold as money, $M$, or invest in assets, $A$, that give him the right to the proceeds of a long-term project. In period 1, the agent learns whether his immediate desire for liquidity, i.e., money, is either high or low. The project pays out its proceeds in period 2 whereby the (expected) return is given as $R$. Denote by $\pi(H) \in(0,1)$, respectively $\pi(L)=1-\pi(H)$, the probability that the agent has high, respectively, low desire for liquidity. Formally, the agent maximizes the following expected utility function

$$
E U(M, A)=\beta_{H} \cdot M \cdot \pi(H)+\beta_{L} \cdot M \cdot \pi(L)+R \cdot A+c
$$

subject to the budget constraint

$$
I_{0}=M+A=1
$$

The constant $c$ thereby denotes the expected utility from period 1 income $I_{1}$ and is defined as

$$
c \equiv\left[\beta_{H} \cdot \pi(H)+\beta_{L} \cdot \pi(L)\right] \cdot I_{1} .
$$


The utility weights $\beta_{H}$ and $\beta_{L}$ measure the liquidity desire of the high, respectively, low type whereby we impose the following assumption on the parameter values:

Assumption. It holds for the model parameters that

$$
1<\beta_{L}<R<\beta_{H}
$$

A possible interpretation of the above scenario would be that the agent learns in period 1 about a short-term investment opportunity which either gives him a low, $\beta_{L}$, or a high, $\beta_{H}$, instantaneous return on every unit of money he invests in period 1 . Since the long-term investment project is, by assumption, illiquid in the sense that there is no way of turning these assets into money before period 2, the agent of this autarkic situation will hold all his period 0 income as money whenever

$$
\pi(L) \cdot \beta_{L}+\pi(H) \cdot \beta_{H}>R
$$

resulting in the expected utility

$$
E U^{\text {aut }}\left(M^{*}=1, A^{*}=0\right)=\beta_{H} \cdot M \cdot \pi(H)+\beta_{L} \cdot M+c .
$$

If, instead, the strict inequality is reversed, he will invest all his period 0 money in assets obtaining expected utility

$$
E U^{\text {aut }}\left(M^{*}=0, A^{*}=1\right)=R+c .
$$

In this autarkic investment situation assets as well as money could only be simultaneously held in equilibrium when the l.h.s. and the r.h.s. in (4) coincide so that the agent is indifferent between holding money and investing in assets.

Consider now a situation with a large population of ex-ante identical agents. More specifically, we associate agents with the points in the unit interval whereby we assume that the law of large numbers applies to the effect that in period 1 a mass $\tau=\pi(H)$ of agents will have a high desire and a mass $1-\tau=\pi(L)$ of agents will have a low desire for liquidity. ${ }^{3}$ If all agents pool in period 0 their initial wealth with a welfare maximizing

\footnotetext{
${ }^{3}$ That the individual probability of an agent to turn out as a high type coincides (almost surely) with the fraction of high types in the population, is for a countably infinite population justified by the law of large numbers together with the assumption that agents' types are i.i.d. While such justification is - for measure-theoretic reasons (cf, e.g., Judd 1982, Duffie and Sun 2007) — not at hand for the continuous population of our model, we simply follow here the literature and misquote the law of large numbers in the 'usual way'.
} 
financial intermediary who can observe each agent's true type, this intermediary would maximize

$$
\begin{aligned}
& E U^{1 s t}(A(H), A(L), M(L), M(H)) \\
= & \left(\beta_{H} \cdot M(H)+R \cdot A(H)\right) \cdot \tau+\left(\beta_{L} \cdot M(L)+R \cdot A(L)\right) \cdot(1-\tau)+c
\end{aligned}
$$

subject to the budget constraint

$$
\tau \cdot(A(H)+M(H))+(1-\tau) \cdot(A(L)+M(L))=1
$$

where $M(t)$, respectively $A(t)$, denotes the amount of money, respectively assets, that is allocated in period 1 to each agent of type $t \in\{H, L\}$. The following solution to this maximization problem follows easily from assumption (3).

Proposition 1: If liquidity types are observable by the financial intermediary, the first best allocation is given by

$$
\begin{aligned}
A^{*}(H) & =A^{*}(L)=M^{*}(L)=0 \\
M^{*}(H) & =\frac{1}{\tau} .
\end{aligned}
$$

The agent's expected utility is then given as

$$
E U^{1 s t}\left(A^{*}(H), A^{*}(L), M^{*}(L), M^{*}(H)\right)=\beta_{H}+c .
$$

Observe that, by assumption (3), $E U^{1 s t}>E U^{A u t}$. A financial intermediary could thus strictly improve the ex-ante expected utility of a large population of risk-neutral agents by exploiting the budget constraints under the assumption that he can observe the agents' true types. In what follows we consider the - more realistic - case that the agents' liquidity types are private information rather than observable by the financial intermediary.

Remark 1. The standard approaches of Bryant (1980) and Diamond and Dybvig (1983) consider (strongly) risk-averse agents whereby welfare-maximizing allocations implemented by financial intermediation are motivated as optimal "risk-sharing" allocations that provide "liquidity insurance". In contrast, Proposition 1 shows that a financial intermediary can strictly improve welfare in terms of agents' ex ante expected 
utility even in a risk-neutral environment for which insurance considerations do not matter. ${ }^{4}$ A similar, i.e., risk-neutral, model as our basic set-up is published in Chapter 7 of Eichberger and Harper (1997) and appeared - to the best of my knowledge - at first in the unpublished working papers by Eichberger and Milne (1991) and by Eichberger (1992).

Remark 2. At a first glance it might be surprising why the law of large numbers enters into a welfare-maximization argument about risk-neutral agents. To see the economic rationale behind Proposition 1 consider the simple situation of only two risk-neutral agents who will each earn in period 2 a profit of 1 . Further assume that exactly one of these agents will die before consuming the profit in period 2 (i.e., $\beta_{L}=0$ ) whereby each agent's probability of premature death is $\pi(L)=0.5$. Clearly, both agents can maximize their respective ex-ante expected utility through a contract according to which the survivor gets the non-surviving agent's period 2 profit on top of his own profit. The resulting ex-ante expected utility from such arrangement is given as $E U=\beta_{H} \cdot 0.5 \cdot 2$ instead of only $E U=\beta_{H} \cdot 0.5 \cdot 1$ obtainable in the autarkic situation. A similar argument gives rise to the optimal allocation (8)-(9) whereby the law of large numbers ensures that the number of "non-surviving agents", and thereby their monetary resources which can be allocated to the "survivors", is pinned down with certainty in the intermediary's budget constraint.

\section{Implementation of the second best allocation through a demand deposit scheme}

The first best allocation (8)-(10) is no longer implementable whenever the agents' liquidity desire is private information because agents with a low desire for liquidity would pretend to be of a high rather than a low type. In order to identify the second best allocation it is, by the revelation principle, sufficient to consider a direct mechanism where every agent truthfully reveals his type. Suppose now that every agent reports to a financial intermediary some type $\vartheta \in\{h, l\}$ where $h$ stands for reporting a $h i g h$ and $l$ for reporting a low type. The following incentive compatibility conditions for high, respectively low, types are then relevant to our model:

\footnotetext{
${ }^{4}$ As one referee correctly pointed out: Whereas the very specific preference-structure of the DiamondDybvig model even allows for an implementation of the first-best allocation under asymmetric information, maximization under asymmetric information can in our model - in line with the standard literature - only achieve a second best allocation.
} 
$\mathrm{IC}(\mathrm{H})$ :

$$
\begin{aligned}
& R \cdot A(h)+\beta_{H} \cdot M(h) \\
\geq \quad & R \cdot A(l)+\beta_{H} \cdot M(l)
\end{aligned}
$$

$\mathrm{IC}(\mathrm{L})$ :

$$
\begin{aligned}
& R \cdot A(l)+\beta_{L} \cdot M(l) \\
\geq & R \cdot A(h)+\beta_{L} \cdot M(h)
\end{aligned}
$$

Provided that these incentive compatibility conditions hold, a welfare maximizing financial intermediary maximizes

$$
\begin{aligned}
& E U^{2 n d}(A(h), A(l), M(l), M(h)) \\
= & \left(\beta_{H} \cdot M(h)+R \cdot A(h)\right) \cdot \tau+\left(\beta_{L} \cdot M(l)+R \cdot A(l)\right) \cdot(1-\tau)+c
\end{aligned}
$$

subject to the budget constraint

$$
\tau \cdot(A(h)+M(h))+(1-\tau) \cdot(A(l)+M(l))=1 .
$$

$M(\vartheta)$, respectively $A(\vartheta)$, denote here the amount of money, respectively assets, that is allocated in period 1 to each agent who reports type $\vartheta \in\{h, l\}$. By assumption (3), any optimum requires $A^{*}(h)=M^{*}(l)=0$. Furthermore, IC(L) must be binding, i.e., hold with equality, since in an optimum $M(h)$ will be chosen as great as possible without violating incentive compatibility conditions. In an optimum, we therefore have

$$
R \cdot A(l)=\beta_{L} \cdot M(h)
$$

implying, by the budget constraints,

$$
M(h)=\frac{1-(1-\tau) \cdot A(l)}{\tau} .
$$

Substitution then yields for the optimal amounts of money, respectively assets, allocated to the high, respectively, low types

$$
\begin{aligned}
R \cdot A^{*}(l) & =\beta_{L} \cdot M^{*}(h) \Leftrightarrow \\
A^{*}(l) & =\frac{\beta_{L}}{\beta_{L} \cdot(1-\tau)+R \cdot \tau} \Leftrightarrow \\
M^{*}(h) & =\frac{R}{\beta_{L} \cdot(1-\tau)+R \cdot \tau} .
\end{aligned}
$$

The following proposition collects the above results. 
Proposition 2: If liquidity types are not observable by the financial intermediary, the second best allocation is given by

$$
\begin{aligned}
A^{*}(h) & =M^{*}(l)=0, \\
A^{*}(l) & =\frac{\beta_{L}}{\beta_{L} \cdot(1-\tau)+R \cdot \tau}, \\
M^{*}(h) & =\frac{R}{\beta_{L} \cdot(1-\tau)+R \cdot \tau} .
\end{aligned}
$$

The agent's expected utility is then given as

$$
\begin{aligned}
& E U^{2 n d}\left(A^{*}(h), A^{*}(l), M^{*}(l), M^{*}(h)\right) \\
= & \frac{\beta_{L} \cdot(1-\tau)}{\beta_{L} \cdot(1-\tau)+R \cdot \tau} \cdot R+\frac{R \cdot \tau}{\beta_{L} \cdot(1-\tau)+R \cdot \tau} \cdot \beta_{H}+c .
\end{aligned}
$$

Observe that $E U^{\text {aut }}<E U^{2 n d}<E U^{1 s t}$. Thus, while the second best allocation does not achieve the ex-ante expected utility of the first best allocation it is still a strict improvement over the autarkic investment situation. Furthermore, observe that a standard demand deposit contract of a bank - which guarantees real interest rates $r_{1}, r_{2} \geq 0$ for the agents' deposits in periods 1 and 2-may result in this second best allocation. In particular, the following interest rates

$$
\begin{aligned}
1+r_{1} & =\frac{R}{\beta_{L} \cdot(1-\tau)+R \cdot \tau} \\
1+r_{2} & =\beta_{L}
\end{aligned}
$$

would then give rise to a demand deposit scheme that generates the second best allocation of Proposition 2 whereby (21) follows from (20) together with

$$
\left(1+r_{1}\right) \cdot\left(1+r_{2}\right)=\frac{\beta_{L}}{\beta_{L} \cdot(1-\tau)+R \cdot \tau} \cdot R .
$$

\section{Introducing the possibility of becoming a rene- gade agent}

Although the second best allocation of Proposition 2 is, by construction, incentive compatible, it is not clear in how far it is sustainable when alternative actions become available to the agents in period 0 . In this section, we will investigate whether the optimal demand deposit scheme (16)-(18) is implementable in a subgame-perfect Nash equilibrium under the relaxed participation constraint that any agent can alternatively make in period 0 a private investment whereby he has in period 1 full access to an 
ex-post asset market. Provided that all other agents participate in the demand deposit scheme (16)-(18), such a renegade agent could then sell his asset on the ex-post asset market to scheme-participating agents as prospective buyers. In this section we formally characterize the period 0 decision situation of an agent of either becoming a renegade agent or not.

Let us suppose - somewhat informally - that there are relevant subgame asset markets in period 1 at which a renegade agent manages to sell the assets of his private long-term investment project which entitle to payoff $R$ in period $2 .^{5}$ At first observe that there is no subgame-perfect equilibrium in which a renegade agent with low liquidity desire could do better by selling rather than keeping his assets. As a consequence, any renegade agent who sells his assets in such a subgame must have a high desire for liquidity. More specifically, suppose that the subgame results in some equilibrium price $p^{*}$. From his ex-ante perspective, an agent will then have a strict incentive for not participating in the demand deposit scheme, i.e., becoming a renegade agent, if and only if

$$
E U^{r e n}\left(p^{*}\right)>E U^{2 n d}
$$

such that

$$
E U^{r e n}\left(p^{*}\right)=R \cdot(1-\tau)+p^{*} \cdot \beta_{H} \cdot \tau+c .
$$

$E U^{r e n}\left(p^{*}\right)$ stands here for the renegade agent's ex-ante expected utility that obtains whenever he sells his assets in the asset market at equilibrium price $p^{*}$. Given these preliminary observations we are now able to characterize the sustainability of the demand deposit scheme in terms of the equilibrium price $p^{*}$ that obtains in the ex-post market.

Proposition 3: Define the following threshold level

$$
t^{*} \equiv \frac{\beta_{H}-R+\beta_{L} \cdot(1-\tau)+R \cdot \tau}{\beta_{L} \cdot(1-\tau)+R \cdot \tau} \cdot \frac{R}{\beta_{H}} .
$$

1. No agent has a strict incentive to become a renegade and deviate from the demand deposit scheme (16)-(18) if he can only sell his assets at an equilibrium price $p^{*}$ in the subgame market situation such that $p^{*} \leq t^{*}$.

2. Conversely, if there is some agent who can sell his assets at an equilibrium price $p^{*}$ such that $p^{*}>t^{*}$, then this agent has a strict incentive to become a renegade agent.

\footnotetext{
${ }^{5}$ Without loss of generality, we can neglect subgames in which the renegade agent does not trade assets since they do not give rise to a higher expected utility than the autarcic investment situation.
} 
Proof: The renegade agent has no strict incentive to deviate from (16)-(18) if and only if

$$
\begin{aligned}
E U^{2 n d} \geq & E U^{r e n}\left(p^{*}\right) \Leftrightarrow \\
& \frac{\beta_{L}}{\beta_{L} \cdot(1-\tau)+R \cdot \tau} \cdot R \cdot(1-\tau)+\frac{R}{\beta_{L} \cdot(1-\tau)+R \cdot \tau} \cdot \beta_{H} \cdot \tau \\
\geq & R \cdot(1-\tau)+p^{*} \cdot \beta_{H} \cdot \tau
\end{aligned}
$$

whereby this inequality is mathematically equivalent to

$$
\frac{\beta_{H}-R+\beta_{L} \cdot(1-\tau)+R \cdot \tau}{\beta_{L} \cdot(1-\tau)+R \cdot \tau} \cdot \frac{R}{\beta_{H}} \geq p^{*} .
$$

This proves Proposition 3.

Proposition 3 is an important intermediate result of our paper because it demonstrates that sustainability of the second best liquidity allocation through a demand deposit scheme exclusively depends on the price obtainable in the ex-post asset market. Whether the equilibrium price $p^{*}$ is below or above the critical threshold value (25) depends thereby on the way we model such ex-post asset market. In the following two sections we investigate two different scenarios which both endogenize such ex-post asset market within our model set-up whereby the determination of $p^{*}$ strongly depends on whether the future income $I_{1}$ is either high or low.

\section{Sustainability of the second best allocation in the case of high future income}

In the previous section we have determined that an agent has an incentive to become a renegade agent in period 0 , if he can expect in period 1 a price for his asset that is above the threshold value (25). Let us now jump to this ex-post asset market situation in order to investigate which equilibrium price $p^{*}$ may plausibly emerge. We thereby make in this section the crucial assumption that the potential buyers for this asset do not face any relevant budget constraints with respect to their period 1 liquidity. More precisely, we assume throughout this section that the agents' period 1 income is sufficiently large in the sense that

$$
\frac{R}{\beta_{L}} \leq I_{1} .
$$

Recall from the previous section that any prospective seller of an asset has to be a renegade agent with a high desire for liquidity. Conversely, only agents with a low 
desire for liquidity would buy in any subgame-perfect Nash equilibrium the asset from the renegade agent. Intuitively, high type agents are happy with the amount of money allocated to them by the financial intermediary whereas low type agents are "exploited" by their binding incentive compatibility condition. Moreover, it is easy to verify that the renegade agent cannot make any attractive offer to high type agents at which he himself would be willing to sell his asset. As a consequence, the only relevant trading partners we have to consider are a high-type renegade agent and low-type scheme-participants.

Any high type renegade agent would sell his asset at some price $p^{*}$ iff

$$
p^{*} \geq \frac{R}{\beta_{H}},
$$

so that his reservation price is given as $\frac{R}{\beta_{H}}$. When a low-type scheme-participating agent buys the asset at price $p^{*}$ his utility is given as

$$
E U^{\text {low }}\left(p^{*}\right)=A^{*}(l) \cdot R+\left(I_{1}-p^{*}\right) \cdot \beta_{L}+R
$$

whenever his period 1 income is sufficiently high, i.e., whenever $I_{1} \geq p^{*}$. If, instead, this agent does not purchase the asset, he settles for utility

$$
E U^{\text {low }}=A^{*}(l) \cdot R+I_{1} \cdot \beta_{L} .
$$

As a consequence, the low type scheme-participating agent with sufficiently high income wants to buy the asset iff

$$
\begin{aligned}
E U^{\text {low }}\left(p^{*}\right) & \geq E U^{\text {low }} \\
& \Leftrightarrow \\
p^{*} & \leq \frac{R}{\beta_{L}} .
\end{aligned}
$$

The prospective buyer's maximal willingness-to-pay is therefore $\frac{R}{\beta_{L}}$ whereby assumption (29) formally ensures that any buyer can actually afford the asset at such high price.

By the above considerations, every ex-post asset-market equilibrium price $p^{*}$ has to satisfy

$$
p^{*} \in\left[\frac{R}{\beta_{H}}, \frac{R}{\beta_{L}}\right],
$$

whereby $p^{*}=\frac{R}{\beta_{L}}$ stands for the case where the seller (i.e., the high type renegade agent) has full market power whereas $p^{*}=\frac{R}{\beta_{H}}$ describes the converse situation where the buyer (i.e., a low type scheme-participating agent) has full market power. In order to further formalize this concept of 'market-power', let us consider the following family of possible ex-post market asset-prices

$$
p_{\alpha}^{*}=\alpha \cdot \frac{R}{\beta_{L}}+(1-\alpha) \cdot \frac{R}{\beta_{H}}, \alpha \in[0,1]
$$


where the parameter $\alpha$ is a measure for the renegade agent's market-power on the ex-post asset market.

Proposition 4: Define the following threshold

$$
0<\alpha^{*} \equiv\left(\frac{\beta_{L}}{\beta_{L} \cdot(1-\tau)+R \cdot \tau}\right) \cdot\left(\frac{\beta_{H}-R}{\beta_{H}-\beta_{L}}\right)<1 .
$$

An agent has a strict incentive to become a renegade and deviate from the demand deposit scheme (16)-(18) if and only if his market-power is sufficiently high in the sense that we have for the market-power parameter $\alpha>\alpha^{*}$.

Proof: An agent has a strict incentive to become a renegade agent iff

$$
\begin{aligned}
p_{a}^{*} & >t^{*} \Leftrightarrow \\
\alpha \cdot \frac{R}{\beta_{L}}+(1-\alpha) \cdot \frac{R}{\beta_{H}} & >\frac{\beta_{H}-R+\beta_{L} \cdot(1-\tau)+R \cdot \tau}{\beta_{L} \cdot(1-\tau)+R \cdot \tau} \frac{R}{\beta_{H}}
\end{aligned}
$$

which is mathematically equivalent to the inequality

$$
\alpha>\left(\frac{\beta_{L}}{\beta_{L} \cdot(1-\tau)+R \cdot \tau}\right) \cdot\left(\frac{\beta_{H}-R}{\beta_{H}-\beta_{L}}\right) \equiv \alpha^{*} .
$$

Finally, observe that indeed

$$
\alpha^{*} \in(0,1)
$$

because, by our assumption $1<\beta_{L}<R<\beta_{H}$,

$$
\left(\frac{\beta_{L}}{\beta_{L} \cdot(1-\tau)+R \cdot \tau}\right) \in(0,1) \text { and }\left(\frac{\beta_{H}-R}{\beta_{H}-\beta_{L}}\right) \in(0,1) \text {. }
$$

Proposition 4 links the sustainability of a second best allocation through a demand deposit scheme to a prospective renegade agent's market power on the ex-post asset market. On the one hand, Proposition 4 can therefore be read as a relevant qualification of the 'Jacklin critique'. Namely, whereas Jacklin claims that the mere possibility of an expost asset market implies the unsustainability of the second best allocation, Proposition 4 establishes that the question of sustainability rather depends on the renegade agent's market power on the ex-post asset market. If this market power is sufficiently low, i.e., if $\alpha$ is below the threshold value (37), then a demand deposit scheme can sustainably implement the second best allocation. 
On the other hand, however, Proposition 4 can also be read as a re-confirmation of Jacklin's critique. Namely, under our assumption of a high period 1 income, the potential demand-side for the renegade's asset is given by the whole population of low type agents so that the prospective seller would thus face a large number of potential buyers with high liquidity resources. Standard argumentation from Bertrand price competition makes it plausible that these potential buyers engage in a fierce bidding competition to the effect that the renegade agent gains full market power, i.e., $\alpha=1$, and sells the asset at the

high price $p^{*}=\frac{R}{\beta_{L}}$. The following result is an immediate consequence of Proposition 4 because of $\alpha^{*}<1$.

Proposition 5: If there is Bertrand price competition between prospective buyers on the ex-post asset market, then the demand deposit scheme (16)-(18) is not sustainable in the case of high future income.

To sum up: Proposition 4 shows that not the possible existence of an ex-post asset market per sé but rather the renegade agent's market power may destroy the sustainability of a welfare maximizing demand deposit scheme. In addition, however, Proposition 5 suggests that the most plausible scenario in the case of high future income is a renegade agent with a lot of market power. As a consequence, the Jacklin critique appears to be a valid argument against the sustainability of a welfare maximizing demand deposit scheme whenever the low type agents' period 1 income provides them with enough liquidity to purchase the asset at a high price on the ex-post market.

\section{Sustainability of the second best allocation in the case of low future income}

Because of the assumption of a high future income, i.e.., $I_{1}>\frac{R}{\beta_{L}}$, the previous section's potential demand-side for the asset on some ex-post market was given by all low-type agents who could, by assumption, afford to pay a price up to $\frac{R}{\beta_{L}}$. In this section we consider the situation of low future income whereby we focus on the interesting benchmark case where $I_{1}=0$. Under the assumption of low future income, only agents who receive liquidity through the demand deposit scheme by reporting a high type are able to buy the asset on some ex-post market in period 1. Although a low type agent's maximal willingness-to-pay is still $\frac{R}{\beta_{L}}$, he can now - in contrast to the high income scenario- only afford to buy up to a price that equals the liquidity which he obtains by misreporting 
his type. That is, the maximal price he is able to pay on the ex-post market is given by his liquidity constraint

$$
M^{*}(h)<\frac{R}{\beta_{L}}
$$

Assumption. If there is more than one prospective buyer in the ex-post asset market, i.e., $n>1$, then these prospective buyers engage in Bertrand price competition to the effect that the renegade agent can sell the asset at the maximal price

$$
p^{* *}=M^{*}(h) \equiv \frac{R}{\beta_{L} \cdot(1-\tau)+R \cdot \tau}
$$

to a randomly selected buyer.

Suppose that $n>1$ low-type agents misreport their type in order to compete with liquidity $M^{*}(h)$ on the demand-side of the ex-post asset market. By the above Bertrand price competition assumption, the expected utility of any such agent is given as

$$
\begin{aligned}
E U^{\text {low }}\left(p^{* *}, n\right) & =\frac{1}{n}\left(\left(M^{*}(h)-p^{* *}\right) \cdot \beta_{L}+R\right) \\
& =\frac{1}{n} \cdot R
\end{aligned}
$$

whereby we assume that each prospective buyer has an equal chance of $\frac{1}{n}$ to buy the asset. In contrast, if a low type agent sticks with the demand deposit scheme (16)-(18), his utility is

$$
\begin{aligned}
\operatorname{EU}^{\text {low }}\left(A^{*}(l)\right) & =A^{*}(l) \cdot R \\
& =\frac{\beta_{L}}{\beta_{L} \cdot(1-\tau)+R \cdot \tau} \cdot R .
\end{aligned}
$$

The following proposition establishes that a sufficiently large difference between the parameter-values $\beta_{L}$ and $R$ may give more than one low type agent a strict incentive to misreport his type in a Nash equilibrium to the effect that the renegade agent can secure himself the maximal price (44) on the ex-post asset market.

Proposition 6: Suppose that we have for the model parameters $\beta_{L}, R, \tau$ that

$$
\frac{\beta_{L}}{\beta_{L} \cdot(1-\tau)+R \cdot \tau}<\frac{1}{2} .
$$

If there is Bertrand price competition between prospective buyers on the ex post asset market, then the demand deposit scheme (16)-(18) is not sustainable in the case of low future income. 
Proof. As a consequence of the Bertrand price competition assumption for the ex-post market subgame, the scheme-participating low types' decisions whether to misreport their type or not amounts to a coordination game. The equilibrium number $n^{*}$ of prospective buyers - i.e., low type agents who misreport their type in order to be able to trade on the ex-post asset market - in any pure-strategy Nash equilibrium of this coordination game is the largest natural number such that ${ }^{6}$

$$
\begin{aligned}
E U^{\text {low }}\left(p^{* *}, n^{*}\right) & >\operatorname{EU}^{\text {low }}\left(A^{*}(l)\right) \\
& \Leftrightarrow \\
\frac{1}{n^{*}} & >\frac{\beta_{L}}{\beta_{L} \cdot(1-\tau)+R \cdot \tau},
\end{aligned}
$$

whenever $n>1$. Thus, if (49) is satisfied, we have that $n^{*}>1$ so that the renegade agent would sell the asset, by the Bertrand price competition assumption, at price (44). To see that this ex-post market equilibrium price would give a strict ex-ante incentive for becoming a renegade observe that

$$
\begin{aligned}
p^{* *} & >t^{*} \\
\frac{R}{\beta_{L} \cdot(1-\tau)+R \cdot \tau} & >\frac{\beta_{H}-R+\beta_{L} \cdot(1-\tau)+R \cdot \tau}{\beta_{L} \cdot(1-\tau)+R \cdot \tau} \frac{R}{\beta_{H}} \\
& \Leftrightarrow \\
R & >\beta_{L} \cdot(1-\tau)+R \cdot \tau,
\end{aligned}
$$

which is always satisfied. Under condition (49), an agent will have a strict ex-ante incentive to become a renegade agent in order to sell his asset on the ex-post asset market to low-type scheme-participants who have themselves a strict incentive to misreport their type in order to compete with each other on the ex-post asset market. $\square$

In case (49) is not satisfied, the situation is different. Namely, if

$$
\frac{\beta_{L}}{\beta_{L} \cdot(1-\tau)+R \cdot \tau} \geq \frac{1}{2},
$$

there will be exactly one prospective buyer in the ex-post market in any Nash equilibrium of the above coordination game. Instead of a Bertrand price competition between several prospective buyers - thereby giving full market power to the renegade agent - it is most

\footnotetext{
${ }^{6}$ We consider strict inequality because we stipulate for the case of indifference that the schemeparticipants stay with the scheme rather than misreport their type.
} 
plausible to endogenize this ex-post market situation as a bilateral bargaining situation between a high type renegade agent, on the one hand, and a low type agent who has misreported his type, on the other hand.

For technical convenience we formally describe such bilateral bargaining as an ultimatum bargaining situation. ${ }^{7}$ The 'market power' parameter $\alpha$ stands here for the probability that the seller (=the renegade agent) will be in the position of making a take-it-or-leave-it (=TOL) offer whereas $(1-a)$ stands for the probability that the buyer (=the low type agent) will make such an TOL offer. Because the seller could, in this low income situation, maximally ask for price $\frac{R}{\beta_{L} \cdot(1-\tau)+R \cdot \tau}$ and the buyer would maximally offer price $\frac{R}{\beta_{H}}$, the expected equilibrium price on the ex-post asset market is given as

$$
p_{\alpha}^{* *}=\alpha \cdot \frac{R}{\beta_{L} \cdot(1-\tau)+R \cdot \tau}+(1-\alpha) \cdot \frac{R}{\beta_{H}} \text { with } \alpha \in[0,1] .
$$

In order to focus the subsequent analysis, we consider the - plausible - symmetric case in which both agents have an ex-ante equal chance of making an TOL.

Assumption. We suppose that both agents have identical bargaining power, i.e., $\alpha=$ 0.5, so that the expected equilibrium price on the ex-post asset market is given as

$$
p_{0.5}^{* *}=\frac{1}{2} \cdot \frac{\beta_{H}+\beta_{L} \cdot(1-\tau)+R \cdot \tau}{\beta_{L} \cdot(1-\tau)+R \cdot \tau} \cdot \frac{R}{\beta_{H}} .
$$

The following Theorem state the paper's main result according to which a welfare maximizing demand deposit scheme is sustainable for suitable parameter values $\beta_{L}, R, \beta_{H}$, and $\tau$.

Theorem: Recall our parameter convention $1<\beta_{L}<R<\beta_{H}$ and assume that (55) holds. ${ }^{8}$ If the prospective buyer and seller have identical bargaining power, then the demand deposit scheme (16)-(18) is sustainable if and only if

$$
\tau \geq \frac{2 R-\beta_{H}-\beta_{L}}{R-\beta_{L}} .
$$

\footnotetext{
${ }^{7}$ Without going into the technical details of bargaining theory, observe that alternative interpretations of the parameter $\alpha$ in the pricing formula (36) can be derived from Rubinstein's (1982) infinite horizon alternating bargaining situation in terms of the agents' time-discount factors as well as from the Nash bargaining solution (Nash 1950) in terms of the agents' bargaining power parameters; (also cf., e.g., Kultti 2000, Demougin and Helm 2006).

${ }^{8}$ Observe that inequality (??) holds for all values of $\tau$ if $R \leq 2 \cdot \beta_{L}$.
} 
Proof: No agent has a strict incentive to become a renegade and deviate from the demand deposit scheme (16)-(18) iff

$$
\begin{aligned}
p_{0.5}^{* *} & \leq t^{*} \Leftrightarrow \\
\frac{1}{2} \cdot\left(\frac{\beta_{H}+\beta_{L} \cdot(1-\tau)+R \cdot \tau}{\beta_{L} \cdot(1-\tau)+R \cdot \tau}\right) \cdot \frac{R}{\beta_{H}} & \leq \frac{\beta_{H}-R+\beta_{L} \cdot(1-\tau)+R \cdot \tau}{\beta_{L} \cdot(1-\tau)+R \cdot \tau} \cdot \frac{R}{\beta_{H}},
\end{aligned}
$$

which is mathematically equivalent to

$$
R \cdot(2-\tau) \leq \beta_{H}+\beta_{L} \cdot(1-\tau) .
$$

The Theorem follows easily from an rearrangement of (61)

A formal discussion of the sustainability condition (58) establishes the following relationships between the values of our model parameters $\beta_{L}, R, \beta_{H}$, and $\tau$, on the one hand, and sustainability of a welfare maximizing demand deposit scheme, on the other hand.

1. Fix the parameter values $\beta_{L}, \beta_{H}, R$ and observe that (58) holds if $\tau$ is sufficiently large (=close to one).

2. Fix the parameter values $\beta_{L}, R, \tau$ and observe that (58) holds if $\beta_{H}$ is sufficiently large, i.e., if $\beta_{H}$ satisfies

$$
\beta_{H} \geq R \cdot(2-\tau)-\beta_{L} \cdot(1-\tau) .
$$

3. Fix the parameter values $\beta_{L}, \beta_{H}, \tau$ and observe that (58) holds if $R$ is sufficiently small (=close to $\left.\beta_{L}\right)$.

4. Fix the parameter values $R, \beta_{H}, \tau$ and observe that (58) holds if $\beta_{L}$ is sufficiently small (=close to 1$)$.

As qualitative main insight from the Theorem we can thus conclude: Under the assumption that the scheme-participants have a low future income, the welfare-maximizing demand deposit scheme (16)-(18) is sustainable if there is a large proportion, $\tau$, of agents with a high marginal utility from liquidity, $\beta_{H}$, or if the marginal return of the long-term investment, $R$, is rather low compared to the low type's marginal utility from liquidity, $\beta_{L}$. 


\section{Discussion and concluding remarks}

In the light of the 'Jacklin critique', Hellwig (1994) poignantly asks: "Why are financial intermediaries actually needed?" (p. 1382) and goes on to offer three possible answers: Avoidance of market-transaction costs, a role as commitment device, and the monitoringcost advantage argument by Diamond (1984), see also Hellwig (1998). An alternative rationale for the existence of financial intermediaries - related to the transaction cost argument - is given by Wallace (1988) who argues that an implementation of the second best allocation by a demand deposit scheme is only sustainable when the agents remain isolated from each other in any ex-post situation. Or, positively interpreted: According to Wallace demand deposits exist in circumstances where agents cannot communicate with each other so that the existence of ex-post markets becomes impossible. Finally, Diamond (1997) argues that the assumption of ex-post markets in the sense of Jacklin (1987) but only with limited participation may give rise to a sustainable banking sector.

The present paper's argument on possible merits of financial intermediation differs from the above answers. According to our model a demand deposit scheme can sustainably implement an optimal liquidity allocation whenever prospective renegade agents have a sufficiently low market power on the ex-post asset market. Furthermore, we argue that the renegade agent's market power would be rather low whenever the demand deposit scheme participants have a low future income. That is, although the 'Jacklin critique' appears to be a valid argument for a high future income population, it does not necessarily apply to low future income populations.

The key to our formal findings is a game-theoretically sound description of the expost asset market situation that may arise when a renegade agent does not participate in the demand deposit scheme. Jacklin's original analysis is unsatisfactory in this regard because the origin, and therefore the structure, of such ex-post market situations remain rather unclear except for the claim that this market will be competitive, i.e., renegade agents are price-takers, too. This shortcoming of Jacklin's formal argument had been observed earlier by von Thadden (1999) who writes:

"[...] the 'Jacklin critique' [...], however, was less convincing as it stood, because it considered individual deviations from the banking contract at date 0 , without modelling trading at date 1 (if every agent but one invests in the bank, there is no market!)." (footnote 7)

Von Thadden (1999) proceeds by formally introducing ex-post asset markets into Jacklin's model whereby the existence of such markets is exogenously guaranteed by the assumption that every agent must privately invest some positive fraction of his wealth 
in the investment project. However, since the incentives for private investments are not endogenously derived from the model but rather stated as an ad-hoc assumption, von Thadden's approach is also not fully convincing. In contrast, our approach considers ex-post market subgames in which a renegade agent can trade an asset with agents that actually participate in the bank's demand deposit scheme whereby we have chosen to model such ex-post asset markets in terms of Bertrand price competition and bilateral bargaining situations, respectively. As a consequence, such ex-post markets are not necessarily fully competitive but rather the market power of market participants has an impact on equilibrium prices whereby the budget constraint in terms of future income plays a crucial role when we determine the equilibrium price. Thus, while we agree with the first part of von Thadden's observation about inconsistencies in Jacklin's original analysis, we disagree with his claim that "[...] if every agent but one invests in the bank, there is no market! [...]". It is exactly the careful game-theoretic formalization of such possible ex-post market situations in which one renegade agent may sell his asset to scheme participants that drives our formal findings. 


\section{References}

Bolton, P., and M. Dewatripont (2005) Contract Theory, The MIT Press, Cambridge, Massachusetts.

Bryant J. (1980) "A Model of Reserves, Bank Runs, and Deposit Insurance," Journal of Banking and Finance 4, 335-344.

Demougin, D., and C. Helm (2006) "Moral Hazard and Bargaining Power," German Economic Review 7, 463-470.

Diamond, D.W. (1984) "Financial Intermediation and Delegated Monitoring," Review of Economic Studies 51, 393-414.

Diamond, D.W. (1997) "Liquidity, Banks, and Markets," Journal of Political Economy 105, 928-956.

Diamond, D.W., and P.H. Dybvig (1983) "Bank Runs, Deposit Insurance, and Liquidity," Journal of Political Economy 91, 401-419.

Duffie, D., and Y. Sun (2007) "Existence of Independent Random Matching," The Annals of Applied Probability 17, 386-419.

Eichberger, J. (1992) "A Simple Model of a Bank," Research Paper No.351, University of Melbourne.

Eichberger, J., and F. Milne (1991) "Bank Runs and Capital Adequacy," mimeo, University of Melbourne.

Eichberger, J., and I.R. Harper (1997) Financial Economics, Oxford University Press, Oxford.

Freixas, X., and J.C. Rochet (2008) Microeconomics of Banking, 2nd edn., The MIT Press, Cambridge, Massachusetts.

Goldstein, I., and A. Pauzner (2005) "Demand-Deposit Contracts and the Probability of Bank Runs," Journal of Finance 60, 1293-1327.

Haubrich, J. (1988) "Optimal Financial Structure in Exchange Economics," International Economic Review 29, 217-235.

Haubrich, J., and R. King (1990) "Banking and Insurance," Journal of Monetary Economics 26, 361-386. 
Hellwig, M. (1994) "Liquidity Provision, Banking, and the Allocation of Interest Rate Risk," European Economic Review 38, 1363-1389.

Hellwig, M. (1998) "Banks, Markets, and the Allocation of Risks in an Economy," Journal of Institutional and Theoretical Economics 154, 328-354.

Jacklin, C.J. (1987) "Demand Deposits, Trading Restrictions, and Risk Sharing", chap. II, p. 26-47 in Prescott, E.C., and N. Wallace [eds.] (1987), Contractual Arrangements for Intertemporal Trade, University of Minnesota Press: Minneapolis.

Jacklin, C.J. (1993) "Market Rate versus Fixed Rate Demand Deposits," Journal of Monetary Economics 32, 237-258.

Judd, K.L. (1985) "The Law of Large Numbers with a Continuum of iid Random Variables," Journal of Economic Theory 35, 19-25.

Kultti , K. (2000) "About Bargaining Power," Economics Letters 69, 341 -344.

Nash, J. (1950) "The Bargaining Problem," Econometrica 18, 155-162.

Postlewaite, A., and X. Vives (1987) "Bank Runs as an Equilibrium Phenomenon," Journal of Political Economy 95, 485-491.

Rochet, J.-C., and X. Vives (2004) "Coordination Failures and the Lender of Last Resort: Was Bagehot Right After All?," Journal of the European Economic Association 2, 1116-1147.

Rubinstein, A. (1982) "Perfect Equilibrium in a Bargaining Model," Econometrica 50, 97-109.

Tirole, J. (2006) The Theory of Corporate Finance, Princeton University Press, Princeton, New Jersey.

von Thadden, E.L. (1997) "The Term-structure of Investment and the Banks' Insurance Function," European Economic Review 41, 1355-1374.

von Thadden, E.L. (1998) "Intermediated versus Direct Investment: Optimal Liquidity Provision and Dynamic Incentive Compatibility," Journal of Financial Intermediation 7, 177-197.

von Thadden, E.L. (1999) "Liquidity Creation through Banks and Markets: Multiple Insurance and Limited Market Access", European Economic Review 43, 991-1006. 
Wallace, M. (1988) "Another Attempt to Explain an Illiquid Banking System: The Diamond and Dybvig Model with Sequential Service Taken Seriously," Federal Reserve Bank of Minneapolis, Quarterly Review 12, 3-16.

Wallace, M. (1990) "A Banking Model in Which Partial Suspension Is Best," Federal Reserve Bank of Minneapolis, Quarterly Review 14, 11-24.

Zimper, A. (2006) "Assessing the Likelihood of Panic-based Bank Runs," The B.E. Journal of Theoretical Economics: Vol. 6: Iss. 1 (Contributions), Article 9. 